\title{
O Estágio Curricular Supervisionado I na concepção dos discentes da Licenciatura em Química: Análise das respostas ao questionário da Supervisão do Estágio Curricular
}

The Supervised Internship I in the conception of the Chemistry Degree students: Analysis of the responses to the Curriculum Internship Supervision questionnaire

La Pasantía Supervisada I en la concepción de los alumnos del Curso de Química: Análisis de las respuestas al cuestionario de Supervisión de Pasantías Curriculares

Recebido: 25/07/2021 | Revisado: 01/08/2021 | Aceito: 02/08/2021 | Publicado: 06/08/2021

Sérgio Luís Melo Viroli

ORCID: https://orcid.org/0000-0003-3982-1183 Instituto Federal de Educação, Ciência e Tecnologia do Tocantins, Brasil E-mail:viroli@ifto.edu.br

Gessica Hashimoto de Medeiros ORCID: https://orcid.org/0000-0002-9468-8154 Instituto Federal de Educação, Ciência e Tecnologia do Tocantins, Brasil E-mail:gessica.hm@gmail.com

Nelson Pereira Carvalho ORCID: https://orcid.org/0000-0002-7637-1292 Instituto Federal de Educação, Ciência e Tecnologia do Tocantins, Brasil

E-mail: nelson.pereira.carvalh@gmail.com

Tiago Teixeira Alves

ORCID: https://orcid.org/0000-0002-7807-2085 Universidade Federal do Tocantins, Brasil E-mail: tiagotavessof@gmail.com

Kassio de Jesus Souza

ORCID: https://orcid.org/0000-0001-7234-7837 Universidade Federal do Tocantins, Brasil E-mail:kassiodejesussouza@gmail.com

Yasmim Pereira Sousa

ORCID: https://orcid.org/0000-0003-3897-4866 Instituto Federal de Educação, Ciência e Tecnologia do Tocantins, Brasil E-mail: yasmimp.sousa22@gmail.com

Renildes Santos de Jesus

ORCID: https://orcid.org/0000-0003-0569-0648 Instituto Federal de Educação, Ciência e Tecnologia do Tocantins, Brasil

E-mail:renildescorinthiana@ hotmail.com

Thainara Lima Araújo

ORCID: https://orcid.org/0000-0003-4211-6215 Instituto Federal de Educação, Ciência e Tecnologia do Tocantins, Brasil E-mail: thainara.lima.ara@gmail.com

Amanda Cristina Lança

ORCID: https://orcid.org/0000-0003-2103-523X

Universidade Federal do Tocantins, Brasil

E-mail: amandacristinalanca17@gmail.com

Fernando de Paula e Silva

ORCID: https://orcid.org/0000-0001-6677-0786 Instituto Federal de Educação, Ciência e Tecnologia do Tocantins, Brasil E-mail:fernandinhoheitor@gmail.com

Matheus Lisboa Ramos

ORCID: https://orcid.org/0000-0002-1648-6733 Instituto Federal de Educação, Ciência e Tecnologia do Tocantins, Brasil E-mail: matheus.lisboas13@gmail.com

\section{Resumo}

O Estágio Curricular Supervisionado é fundamental para formação dos acadêmicos da licenciatura em Química, pois oferece condições da aplicação dos saberes acadêmicos oportunizando a prática das competências e desenvolvimento de uma visão crítica da atuação docente. O objetivo deste trabalho foi uma análise das respostas ao questionário aplicado aos concluintes Estágio I, que aconteceu de forma remota nas escolas públicas da Cidade de Paraíso do Tocantins. A pesquisa foi realizada com a participação de 8 (oito) acadêmicos. O questionário virtual foi 
construído na plataforma Google Forms, com questões objetivas e discursivas. A análise do questionário apontou que os discentes estagiaram em escolas públicas, como ótima orientação, boa supervisão e informações sobre os procedimentos e avaliação do estágio, julgaram como significativos os conhecimentos obtidos nas disciplinas do curso durante e anterior a realização do estágio e que o ele proporcionou segurança para atuação em sala de aula. A avaliação do ambiente do estágio foi boa e os professores executaram o planejamento anual com adaptações, ministrando os conteúdos planejados utilizando vídeo aula como recurso tecnológico e que a maioria dos professores das unidades concedentes de estágio não tinham formação ou nenhum conhecimento das TDICs. A importância da realização do Estágio I para a formação docente se resume em oportunizar a vivenciar in loco, despertar a reflexão, criticidade e investigação científica para que o discente inicie sua carreira do magistério com uma formação mais sólida.

Palavras-chave: Prática pedagógica; Avaliação; Regência; Observação; Ensino.

\begin{abstract}
The Supervised Curricular Internship is essential for the formation of undergraduate students in Chemistry, as it offers conditions for the application of academic knowledge, providing opportunities for the practice of skills and the development of a critical view of teaching performance. The objective of this work was an analysis of the answers to the questionnaire applied to Stage I graduates, carried out remotely in public schools in the city of Paraíso do Tocantins. The research was carried out with the participation of 8 (eight) academics. The virtual questionnaire was built on the Google Forms platform, with objective and discursive questions. The analysis of the questionnaire showed that students performed internships in public schools, with excellent guidance, good supervision and information about the procedures and evaluation of the internship, considered significant the knowledge obtained in the course subjects during and before the internship. Provided assurance of classroom performance. The evaluation of the internship environment was good and the professors carried out the annual planning with adaptations, transmitting the planned contents using video classes as a technological resource and that most professors in the internship units did not have training or knowledge in TDIC. The importance of carrying out Practice I for teacher education is summed up in providing opportunities for experiences in loco, awakening reflection, criticality and scientific research so that students can start their teaching career with a more solid training.
\end{abstract}

Keywords: Pedagogical practice; Assessment; Regency; Observation; Teaching.

\title{
Resumen
}

La Pasantía Curricular Supervisada es fundamental para la formación de los estudiantes de pregrado en Química, ya que ofrece condiciones para la aplicación de conocimientos académicos, brindando oportunidades para la práctica de habilidades y el desarrollo de una visión crítica del desempeño docente. El objetivo de este trabajo fue un análisis de las respuestas al cuestionario aplicado a los egresados de la Etapa I, que se llevó a cabo de forma remota en escuelas públicas de la ciudad de Paraíso do Tocantins. La investigación se realizó con la participación de 8 (ocho) académicos. El cuestionario virtual se construyó sobre la plataforma Google Forms, con preguntas objetivas y discursivas. El análisis del cuestionario arrojó que los estudiantes tuvieron pasantías en escuelas públicas, con excelente orientación, buena supervisión e información sobre los procedimientos y evaluación de la pasantía, consideraron significativos los conocimientos obtenidos en las asignaturas del curso durante y antes de la pasantía. Proporcionó seguridad para el desempeño en el aula. La evaluación del entorno de prácticas fue buena y los profesores realizaron la planificación anual con adaptaciones, impartiendo los contenidos planificados utilizando las videoclases como recurso tecnológico y que la mayoría de los profesores de las unidades otorgadoras de prácticas no tenían formación ni conocimiento en TDIC. La importancia de realizar la Práctica I para la formación del profesorado se resume en brindar oportunidades de vivencia in loco, despertando la reflexión, la criticidad y la investigación científica para que los estudiantes puedan iniciar su carrera docente con una formación más sólida.

Palabras clave: Práctica pedagógica; Evaluación; Regencia; Observación; Enseñanza.

\section{Introdução}

A resolução CNE/CP $n^{\circ}$. 02/2015 expedida pelo Conselho Nacional de Educação, instituindo as Diretrizes Curriculares Nacionais para as licenciaturas, determinou os princípios, fundamentos, dinâmica formativa e procedimentos que devem ser considerados nos cursos de formação de professores (Brasil, 2015). Ela ressalta o art. 14, § 4" “o Estágio Curricular Supervisionado é componente obrigatório da organização curricular das licenciaturas, sendo uma atividade específica intrinsecamente articulada com a prática e com as demais atividades de trabalho acadêmico" (Brasil, 2015).

Assim, as licenciaturas devem inserir seus estagiários na educação básica públicas ou particulares com a pretensão de potencializar a prática pedagógica estabelecendo a relação teoria e prática. Nos cursos de licenciatura o estágio é entendido como atividade fundamental na formação profissional dos licenciandos, proporcionando ao futuro professor 
conhecimento do seu local de trabalho, reflexões sobre sua práxis pedagógicas e o diálogo da formação teórica com a prática docente (Silva, Siqueira \& Goi, 2019; Tessaro \& Maceno, 2016).

O estágio supervisionado é fundamental para a formação dos acadêmicos da licenciatura em Química, pois ele oferece ao discente a condições de aplicação de seus saberes acadêmicos em situações da prática educacional, oportunizando a prática de suas competências e desenvolvimento de uma visão crítica da atuação docente (Araújo \& Martins, 2020; Souza \& Ferreira, 2019). Na vivência do ambiente escolar os alunos da licenciatura poderão refletir e comparar as suas convicções educacionais frente aos desafios impostos pela realidade escolar (Freitas \& Monteiro, 2019; Oliveira, 2019). Através do estágio, o futuro docente vivencia a rotina administrativa escolar, a sala de aula, estabelece diálogo com os alunos e interage com o cotidiano do professor adquirindo conhecimento da prática docente (Rocha \& Silva, 2020; Rodrigues, 2018).

O Projeto Pedagógico do Curso Superior de Licenciatura em Química do Instituto Federal de Educação, Ciência e Tecnologia do Tocantins [IFTO] (2020), campus Paraíso do Tocantins, menciona os objetivos pedagógicos do estágio. O PPC considera relevante a reflexão, a adaptação social, e a troca de experiências do estagiário através da prática. "Os objetivos pedagógicos do estágio (...) permita ao estagiário: analisar situações; analisar-se na situação; avaliar as estratégias desenvolvidas; e criar ferramentas inovadoras da prática docente" (IFTO, 2020). De acordo com o Projeto Político do Curso de Licenciatura em Química PPC (IFTO, 2020. p. 57) O Estágio Curricular Supervisionado é:

O Estágio Curricular Supervisionado dos cursos de licenciatura do Instituto de educação Ciências e Tecnologia do Tocantins IFTO é entendido como atividade fundamental na formação profissional dos estudantes, e só terá validade mediante a comprovação de desempenho de atividades relacionadas com a habilitação e atuação futura do estagiário. Deverá ser realizado em unidades escolares públicas ou privadas, de ensino fundamental e/ou médio regular, nas diversas modalidades. Poderá ser realizado no próprio Instituto Federal do Tocantins, em seus campi, desde que o desenvolvimento das atividades permita ampliar os conhecimentos teórico-práticos (IFTO, 2020. p. 57).

O PPC (IFTO, 2020. pp. 57-58), informa a carga horária obrigatória de 400 (quatrocentas e vinte) horas distribuídas em três componentes curriculares (Estágio Curricular Supervisionado I, Estágio Curricular Supervisionado II e Estágio Curricular Supervisionado III).

A carga horária será distribuída nas seguintes atividades: encontros coletivos para estudo teórico e socialização das experiências; visita às escolas para diagnóstico e contato com as equipes pedagógicas responsáveis e com os professores regentes da escola; elaboração de um Plano de Atividades de Estágio (PAE), que norteará as atividades práticas; estágio de observação orientada; participação significativa em projetos da escola; regência, devidamente planejada e supervisionada; elaboração, análise, execução e socialização de projetos de intervenção; elaboração de relatórios semestrais, fruto da reflexão sobre as atividades desenvolvidas, assim como relatórios parciais relativos à evolução das atividades.

Ainda segundo o PPC (IFTO, 2020. pp. 58-59)

O Estágio Curricular Supervisionado I consistirá numa etapa de observação, na qual o estagiário conhecerá toda a infraestrutura (física e pedagógica) em instituição escolar de ensino fundamental ( $6^{\circ}$ ao $9^{\circ}$ ano) estabelecendo contato com as equipes pedagógicas responsáveis e com os Supervisores de Estágio (professor regente da escola); o estagiário elaborará seu plano de atividade de estágio (PAE) que norteará as observações; registrará suas impressões em relatórios parciais e em um relatório final, fruto de e reflexões durante as atividades.

O estágio supervisionado proporciona os futuros professores uma prática do processo escolar. Nessa vivência, há o confronto da realidade com os saberes das disciplinas inseridas na matriz curricular do curso que constituem os currículos dos cursos de licenciatura (Cabral \& Flôr, 2016; Costa, Araújo, Moreira \& Geglio, 2019). Esse confronto é fundamental, pois a formação não deve concentrar somente nos saberes teóricos e o fazer sem reflexão não contribui para a superação dos problemas da educação (Costa et al., 2019). É necessário o rompimento com planejamento político pedagógicas aplicados 
apenas no saber fazer, bem como conviçcões que defendam a teoria como elemento fundamental para a formação, desprezando a importância da produção e práticas pedagógicas no estágio supervisionado (Costa et al., 2016; Dourado 2016).

Referente ao processo da avaliação do discente durante o Estágio Curricular Supervisionado, é imprescindível que seja de modo contínuo, no qual o supervisor do estágio precisará olhar criticamente e realizar orientação aos estagiários quanto às regências, referente à didática, vínculo professor-aluno, métodos de ensino, mediação pedagógica, e disposição mediante aos conflitos, que são desenvolvidos durante o estágio (El Tassa et al., 2015). O supervisor do estágio deve avaliar sistematicamente considerando mais a perspectiva qualitativa, desse modo, o estagiário pode refletir sobre sua conduta, no que diz respeito a sua capacidade e adversidades e aperfeiçoando sua conduta profissional. Cabe ao supervisor de estágio avaliar, refletir, dialogar e trabalhar no estagiário a superação de suas limitações auxiliando o desenvolvimento da pratica profissional. Sendo assim, espera-se que o supervisor avalie, in situ, as condições necessárias à aprendizagem dos estagiários (Mauriz \& Gomes, 2019). Deste modo, O supervisor do Estágio Curricular Supervisionado realiza uma função imprescindível na formação profissional do aluno durante a execução do estágio, pois é possível a orientação e correção do discente durante a realização das atividades desenvolvidas.

Assim, compreendemos que exercício profissional torna se muito mais produtivo no momento que o supervisor do estágio está compromissado com o processo de ensino condicionado o a não se limitar ao plano de técnicas e avaliações burocráticas e precipitadas sobre a atuação do discente durante o estágio (Mauriz \& Gomes, 2019).

Levando em consideração a indispensabilidade da avaliação do processo formativo de modo amplo, englobando a percepção de todos os atores envolvidos, a supervisão do Estágio Curricular Supervisionado do curso de Licenciatura em Química do Instituto Federal de Educação Ciência e Tecnologia do Tocantins campus Paraíso do Tocantins, direciona para uma análise sobre as respostas dos estudantes ao questionário que diz respeito às questões relacionadas a observação, planejamento e realização do Estágio Curricular Supervisionado I, ocorrido de forma remota no segundo semestre de 2020, no ensino fundamental durante a pandemia COVID 19.

Diante do exposto, o objetivo deste trabalho é apresentar uma análise das respostas ao questionário aplicado pela Supervisão do Estágio Curricular Supervisionado, do Curso de Licenciatura em Química do IFTO campus Paraíso do Tocantins, aos estudantes matriculados e que concluíram Estágio Curricular Supervisionado I, que devido ao isolamento social ocasionado pela COVID 19, aconteceu de forma remota no $9^{\circ}$ ano do ensino fundamental em uma escola pública estadual.

\section{Metodologia}

As atividades ocorreram remotamente no período de agosto a dezembro de 2020, após a conclusão do Estágio Curricular Supervisionado I.

\subsection{Tipo de Estudo}

O estudo foi realizado de forma quali-quantitativo, ou seja, abordando a combinação dos processos qualitativos e quantitativos, uma vez que serão expostas informações quantitativas sobre as respostas dos decentes e também a apresentação da avalição das informações (Marconi \& Lakatos, 2015). A pesquisa do tipo qualitativa resulta das interações sociais entendendo os fenômenos humanos através da visão detalhada do pesquisador, enquanto a pesquisa do tipo quantitativa está relacionada a dados estatísticos e comprobatórios (Costa et al, 2019; Mól, 2017). 


\subsection{Local de realização da pesquisa}

O estudo foi realizado no $9^{\circ}$ ano do ensino fundamental em três (03) unidades de ensino concedente do estágio I, públicas, de âmbito estadual, localizadas nos bairros Pouso Alegre, Jardim Paulista e Setor Oeste na Cidade de Paraíso do Tocantins, Estado do Tocantins durante o segundo semestre de 2020 durante a pandemia de Covid-19.

\subsection{Participantes}

A pesquisa foi realizada com a participação de 8 (oito) acadêmicos de ambos os sexos, idades entre 20 a 32 anos, matriculados e concluintes do Estágio Curricular Supervisionado I, ofertada no curso de Licenciatura em Química do Instituto Federal de Educação, Ciência e Tecnologia do Tocantins IFTO campus Paraíso do Tocantins.

\subsection{Instrumento e procedimento de coleta dos dados}

Após a conclusão do Estágio Curricular Supervisionado I, os alunos responderam um questionário virtual, elaborado pela supervisão do estágio do Curso de Licenciatura em Química, construído na plataforma Google Forms, com questões objetivas e discursivas, que foi disponibilizado no WhatsApp no grupo de Estágio Curricular Supervisionado I. O instrumento de coleta de dados utilizado, foi elaborado com o intuito de conhecer a realidade dos(as) sujeitos da pesquisa, referente:

a) A supervisão, orientação, informação, conhecimento e contribuição do Estágio Curricular Supervisionado I;

b) A avaliação da unidade concedente do Estágio Curricular Supervisionado I.

c) Ao planejamento e execução das aulas da unidade concedente de Estágio Curricular Supervisionado I

d) A ministração das aulas da unidade concedente de Estágio Curricular Supervisionado I

Todos os discentes que concluíram o estágio I responderem e devolveram o questionário respondido entre os dias $01 \mathrm{e}$ 07 de dezembro de 2020. A Tabela 1, apresenta as questões que foram respondidas pelos discentes estagiários após conclusão do Estágio Curricular Supervisionado I, no segundo semestre de 2020, na modalidade remota.

Tabela 1 - Questionário utilizado na coleta de dados.

\begin{tabular}{ll}
\hline$N^{\circ}$ & \multicolumn{1}{c}{ Questionário } \\
\hline 01 & Acompanhamento e a supervisão realizados na unidade concedente durante o estágio. \\
02 & Acompanhamento e orientação realizados pelo professor orientador durante o estágio. \\
03 & Clareza das informações fornecidas quanto aos objetivos, procedimentos, relatórios e avaliação do estágio. \\
04 & Conhecimentos obtidos nas disciplinas do curso durante a realização do estágio. \\
05 & Contribuição do estágio para a sua formação profissional e pessoal. \\
06 & Avaliação do ambiente (unidade de ensino concedente) para a realização do estágio curricular. \\
07 & O planejamento dos professores da unidade concedente do estágio para o ano de 2020. \\
08 & Conteúdo ministrado pelos professores da unidade concedente durante o estágio. \\
09 & Recurso tecnológicos utilizados pelos professores da unidade concedente de estágio para ministrar as aulas e se comunicar com os alunos. \\
10 & Conhecimento dos professores da unidade concedente do estágio em tecnologia da informação e comunicação TICs. \\
\hline
\end{tabular}

Fonte: Autores (2020).

\section{Resultados e Discussão}

As análises dos dados do questionário respondidos pelos alunos que realizaram o Estágio Curricular Supervisionado I estão subdivididas em quatro (4) partes. A primeira tem-se a avaliação Orientações, supervisão, informação, conhecimento e contribuição durante o estágio curricular supervisionado I, a segunda aponta-se a avaliação da unidade concedente do estágio, a terceira apresenta-se a ministração das aulas da unidade concedente de estágio e a quarta 
destaca-se as tecnologias digitais informação e comunicação TDIC utilizadas pelos professores. Todas essas situações foram expressas, a seguir, a partir de gráficos.

\subsection{Orientações, supervisão, informação, conhecimento e contribuição durante o estágio curricular supervisionado I.}

O Gráfico 1 demostra que $75 \%$ dos estagiários entrevistados avaliaram a orientação recebida como ótima ou boa e que que tiveram orientação em todas as aulas do estágio.

Gráfico 1 - Avaliação da orientação recebida.

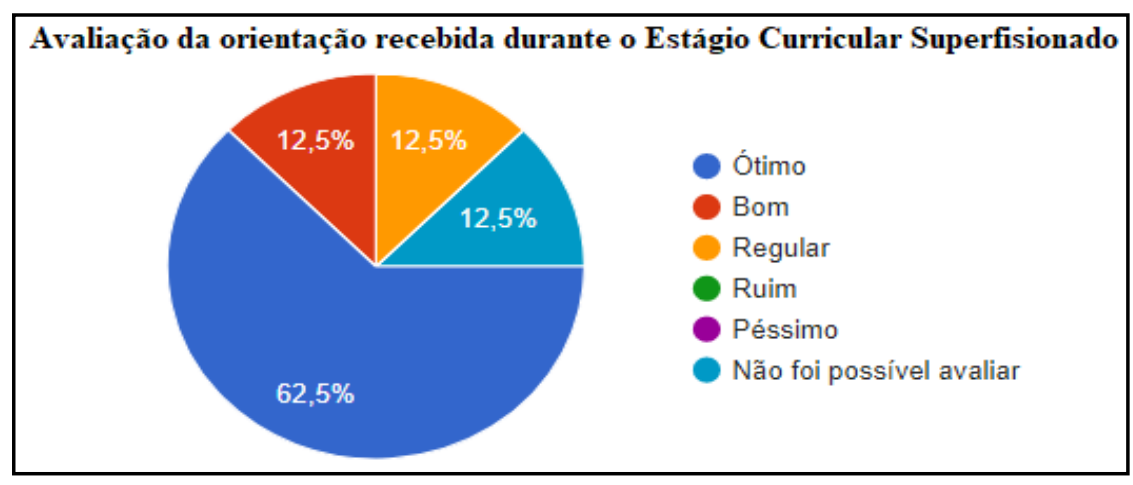

Fonte: Autores (2021).

Segundo o Regulamento do Estágio Curricular Supervisionado dos cursos de graduação presenciais do IFTO (2015), entende-se como Professor Orientador, no caso das licenciaturas, o professor pertencente ao quadro de docentes do Campus, licenciado, ou com formação ou complementação pedagógica ou pós-graduação em educação que deverá dentre outras funções coordenar e acompanhar as atividades desenvolvidas em função do estágio, colaborando com o Supervisor de Estágio da Unidade Concedente em todas as etapas do Estágio Curricular Supervisionado; orientar efetivamente os estagiários em suas atividades e no planejamento e execução de todo o trabalho a ser desenvolvido durante a sua realização; avaliar as atividades dos estagiários; responder pela coerência entre as atividades desenvolvidas pelo estagiário e o Projeto Pedagógico do Curso PPC; indicar fontes de pesquisa e de consulta necessárias à solução de dificuldades encontradas durante as atividades de estágio; VI - informar aos estagiários sobre normas, procedimentos e critérios de avaliação do Estágio Curricular Supervisionado; acompanhar e controlar o cumprimento das horas de Estágio Curricular Supervisionado, assim como receber, analisar e avaliar relatórios e outros documentos; propor soluções para situações emergenciais.

É necessário professores experientes, capacitados e disponíveis para exercer a função de orientador de estágio que enfrentem com competência a aproximação da universidade e escola. Muitas vezes esses profissionais são difíceis de encontrar dentro das instituições (Altarugio \& Neto, 2019; Iza \& Souza Neto, 2015). A insuficiência da orientação durante a pratica do estágio, devido as dificuldades e impossibilidade de realização de visitas regulares às escolas-campo para acompanhamento dos trabalhos dos estagiários, a avaliação dos alunos acaba acontecendo por meio de relatórios e fotografias (Nascimento \& Anselmo 2012, Altarugio \& Neto, 2019).

A assistência realizada pelo orientador do Estágio Curricular Supervisionado deve ser precisa, organizada e ordenada desde a elaboração da aula até a sua execução, avaliando cada etapa do estágio e adequando as necessidades do ensino ao cotidiano da escola (Nascimento \& Anselmo, 2021). A relação entre orientador e orientado estagiário é indispensável para construção a processo ensino aprendizagem, pois o êxito do estágio necessitar muito do suporte dado pelo orientador (Cruz, Silva \& Negreiros, 2020; Nascimento \& Anselmo, 2012). É ainda, importante, no sentido do orientador se colocar como auxiliador na resolução de possíveis problemas surgidos na rotina da prática escolar (Nascimento \& Anselmo, 
2012). Essa relação permite a aproximação e autoconfiança para o estagiário e oportunidades de reflexão para o aluno e orientador, pois diálogo entre ambos na avaliação das práticas exitosas e as experiências mal sucedidas (Nascimento \& Anselmo, 2012).

Os estagiários declararam que tiveram orientação em todas as aulas do estágio. O Gráfico 2 informa que $87 \%$ dos estagiários entrevistados avaliaram a supervisão recebida como ótima ou boa.

Gráfico 2. Avaliação da orientação recebida.

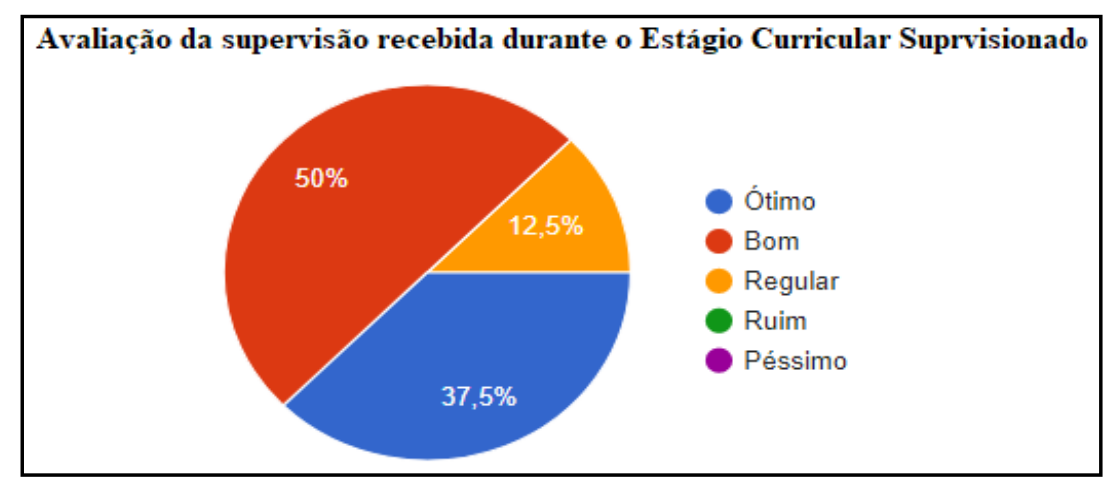

Fonte: Autores (2021).

Ainda segundo o Regulamento do Estágio Curricular Supervisionado dos cursos de graduação presenciais do IFTO (2015), entende-se como Supervisor de Estágio, no caso das licenciaturas, um professor regente da Unidade Concedente do Estágio Curricular Supervisionado, preferencialmente com formação na área de conhecimento desenvolvida no curso do estagiário, que terão as seguintes atribuições elaborar o Plano de Atividades de Estágio junto com o estudante e o professor orientador, acompanhar as atividades que o estudante desenvolverá durante o estágio e avaliar as atividades dos estagiários.

O êxito da pratica curricular resulta da contribuição dos orientadores e supervisores durante o estágio. Segundo Borssoi, (2008) e Pimenta e Lima, (2012), o Estágio Curricular Supervisionado envolve três partes: o estagiário, professor orientador e pelo supervisor, sendo indispensável o envolvimento de todos com a intenção da realização da regência. A mediação do supervisor tem um papel importante na reflexão nos futuros professores. Pimenta e Lima (2012) ressaltam que a mediação do supervisor possui papel importante no processo reflexivo das experiências, possibilidades e do porquê de darem certo ou não durante a vivência no estágio. Sendo assim, o supervisor de estágio colabora com estagiário, observa a suas regências e posteriormente às regências oportuniza ao estagiário um espaço de reflexão sobre suas aulas (Basniak \& Paulek, 2017; Pimenta \& Lima, 2012). Esse instante de reflexão crítica acompanhado com o supervisor conduz o estagiário a analises das suas atitudes, práticas e transformações que poderiam contribuir no progresso da aula e analisar as possíveis explicações para dificuldades encontrados (Basniak \& Paulek, 2017; Imbernón, 2017,). O supervisor de estágio exerce uma forte relevância na etapa do desenvolvimento do licenciando, pois o supervisor de estágio tem a atribuição de proporcionar oportunidades de reflexão sobre a prática do estagiário em sala de aula, mostrando as vulnerabilidade, receio, nervosismo, segurança, superação de sua aula (Basniak \& Paulek, 2017; Pimenta \& Lima 2012).

Quando questionados sobre informações fornecidas quanto aos objetivos, procedimentos, relatórios e avaliação do estágio curricular supervisionado I, o Gráfico 3 informa que 75\% dos discentes avaliaram como ótima ou boa as informações fornecidas durante o estágio. 
Gráfico 3 - Avaliação das Informações recebida.

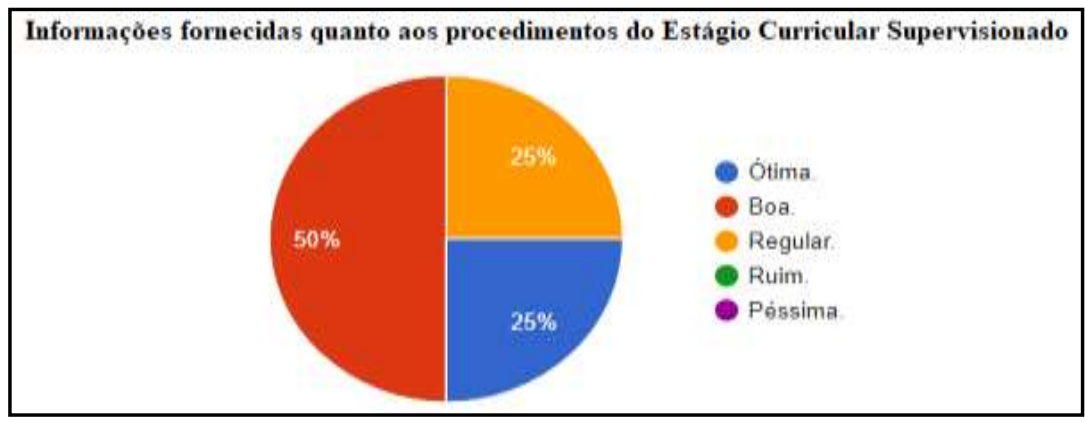

Fonte: Autores (2020).

O Estágio Curricular Supervisionado I consiste numa etapa de observação, na qual o estagiário elaborará seu Plano de Atividade de estágio PAE que norteará as observações; registrará suas impressões em relatórios parciais e em um relatório final, fruto de e reflexões durante as atividades (IFTO, 2020. p. 57). O orientador deve informar aos estagiários sobre normas, procedimentos e critérios de avaliação do Estágio Curricular Supervisionado (IFTO, 2020. p. 57; Nascimento \& Anselmo, 2021).

Com relação ao questionamento sobre os conhecimentos obtidos nas disciplinas do curso de licenciatura serem necessários durante a realização do estágio curricular supervisionado I, o Gráfico 4 demostra que $75 \%$ dos estagiários consideraram com necessários ou significativos esse conhecimento.

Gráfico 4 - Avaliação do conhecimento das disciplinas anterior ao estágio

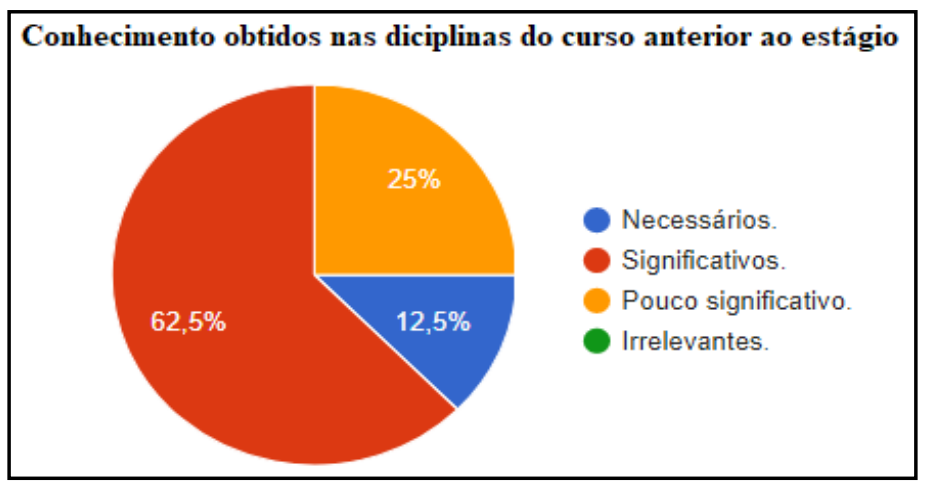

Fonte: Autores (2021).

A realização do estágio curricular supervisionado I requer o conhecimento de todas as disciplinas que envolvem o currículo, pois elas são fundamentais porque trabalham os conhecimentos e métodos a serem desenvolvidos durante a prática e ao longo da carreira profissional (Aroeira \& Pimenta, 2018). Libâneo (2008), afirma que as disciplinas formam um combo de conhecimentos, organizados didática e pedagogicamente, com a finalidade da compreensão e prática dos conceitos pelos discentes. Neste sentido, destaca se os conteúdos relacionados pelos professores no planejamento do Estágio e que conhecimentos são mobilizados pelos alunos (Almeida \& Moreira, 2020).

A partir disso, é necessário ampliar as formas de planejamento das disciplinas de Estágio Curricular Supervisionado, tencionado o aperfeiçoamento da qualidade do ensino, iniciando se em uma avaliação abrangente, incluindo a forma como são desenvolvidas as disciplinas pelos docentes das instituições formadoras dos licenciados, como os professores das unidades concedentes do estágio que aceita e ampara os discentes, de que forma os conhecimentos são socializados pelos acadêmicos nas intervenções (Almeida \& Moreira, 2020). A realização de um seminário antes da realização dos estágios, contribui para a disseminação das informações, dirimir dúvidas e discussões sobre as dificuldades encontradas do estágio. 
Essa situação deve incluir a participação dos docentes orientadores da instituição de Ensino Superior, professores supervisores da unidade concedente de estágio e discentes. Através dessa ação cada participante poderá refletir criticamente sobre a sua participação no processo formativo (Almeida \& Moreira, 2012).

Com relação ao questionamento sobre a contribuição do estágio curricular supervisionado I para a sua formação profissional, o gráfico 5 demostram que 62,5\% dos entrevistados responderam que o estágio proporciona a aquisição de segurança para atuação em sala de aula.

Gráfico 5 - Contribuição do estágio.

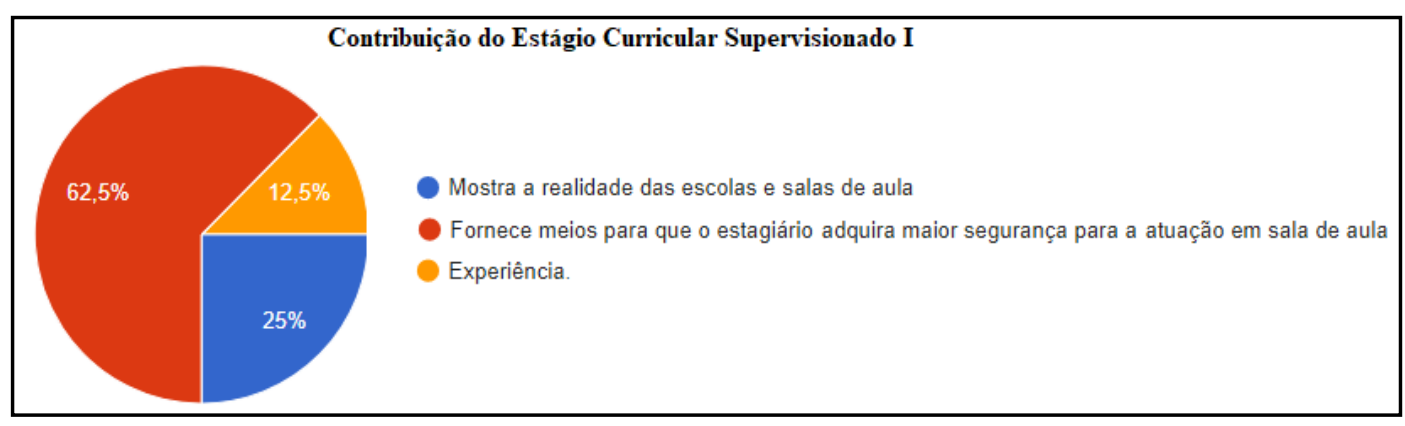

Fonte: Autores (2021).

A partir das respostas obtidas, podemos afirmar que, na visão do aluno, a contribuição do componente curricular está voltada especialmente para a segurança da atuação em sala de aula. Segundo Saviani (2013), afirma que no instante em que o discente compreende que teoria e prática são fundamentais, entendendo o estágio supervisionado, como um espaço, possível a esse treinamento, o futuro professor construirá uma vida profissional satisfatória, ou seja, produzirá um entendimento pleno da atuação cotidiana da atmosfera escolar.

O estágio é uma etapa da formação do licenciado, em que ocorre a relação do estagiário com prática da atividade docente, entendendo, analisando, reflexionando, auxiliando e gerando novos saberes possibilitando uma prática pedagógica significativa (Fonseca, Sena, Mesquita \& Paula, 2019). No momento da realização do estágio supervisionado ocorre a situação oportuna da vivenciar a aprendizagem em sua plenitude, pois é no estágio que o discente usará os saberes obtidos durante sua formação acadêmica, associando com suas vivências sociais e profissionais (Fonseca et al., 2019).

\subsection{Avaliação da unidade concedente do estágio curricular supervisionado I}

Com relação a avaliação do ambiente escolar onde foi realizado o Estágio Curricular Supervisionado I, o Gráfico 6 expressa que $87 \%$ dos alunos avaliaram como bom ou ótimo a unidade concedente de estágio. 
Gráfico 6 - Avaliação do ambiente do estágio curricular supervisionado I.

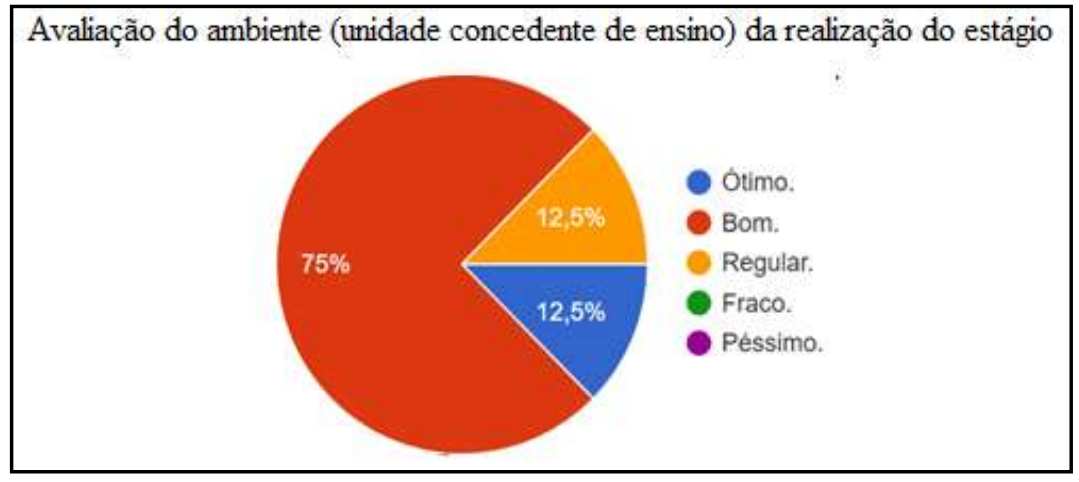

Fonte: Autores (2021).

Uma atmosfera positiva no ambiente escolar favorece o melhor desempenho dos alunos, uma atuação mais ativa dos docentes e gestores da escola, um ambiente saudável e a satisfação de todos os que atuam na escola. Nesse sentido, o clima escolar pode representar um diferencial importante para uma educação de qualidade. Pois, um bom clima escolar apresenta boas relações entre pessoas, um ambiente de cuidado e confiança, espaços de participação e boa comunicação entre os que convivem na escola (Berkowitz et al, 2017). Quando a atmosfera escolar é negativa, representa risco da qualidade da vida escolar, favorecendo os desenvolvimentos de problemas de insatisfação e conflitos interpessoais. Em cada etapa do estágio, o estudante da licenciatura busca compreender o funcionamento do ambiente escolar por meio da observação e da regência sempre sob a orientação e acompanhamento do professor-supervisor da escola e do professor universitário responsável pela disciplina (Cabral \& Flôr, 2016).

O âmbito escolar é a fase inicial desenvolvida no Estágio I, sendo primordial na formação do futuro professor, pois é o período no qual a direção e coordenação da unidade de ensino oportuniza ao aluno estagiário, conviver com a realidade e ambiente escolar, docentes e colaboradores e Projeto Político Pedagógico da unidade de ensino concedente do estágio. Segundo Elali (2003), o meio físico influência de forma direta e metafórica, favorecendo ou dificultando o comportamento de seus ocupantes. Assim sendo, entende se a relevância do conhecimento do âmbito escolar, pois as instalações físicas da escola além de contribuir para a relação social dos professores e alunos também acontece o processo pedagógico em sua plenitude, pois o processo ensino-aprendizagem ocorre em todo ambiente escolar (Carpinteiro \& Almeida, 2008). Portanto, além do convívio com equipe pedagógica, professores, funcionário, alunos e o ambiente físico da unidade de ensino concedente do estágio, é fundamental o conhecimento do Projeto Político Pedagógico da escola.

Muito mais que um conjunto diversificado de modelos e regras contendo atividades e planos de ensino, o Plano Político pedagógico, da unidade de ensino concedente do estágio é fruto da elaboração, vivência e compromisso dos profissionais relacionados com processo educacional da escola (Veiga, 2005).

\subsection{Planejamento e execução das aulas da unidade concedente de estágio curricular supervisionado}

De acordo com o Gráfico 7, os estagiários declarados que 87\% dos professores estavam executando o planejamento anual com adaptações durante o segundo semestre de 2020. 
Gráfico 7 - Planejamento anual dos professores da unidade concedente de estágio.

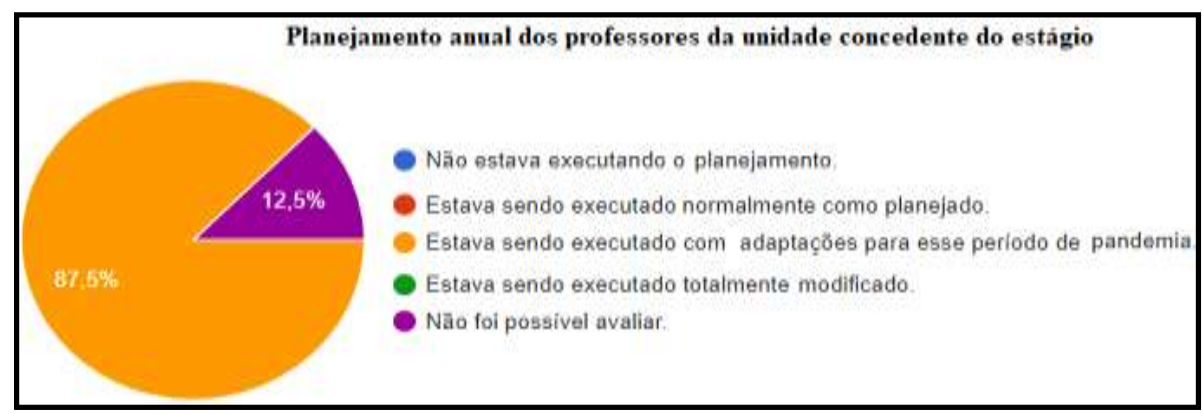

Fonte: Autores (2021).

O segundo semestre de ano letivo de 2020 tornou-se incomum, difícil e adaptativo para os professores durante as exigências de ajuste e adaptação exigida pela pandemia e seu resultante ensino remoto (Oliveira, 2020). O planejamento é um procedimento que justifica a organização e coordenação do exercício da docência, relacionado a atividade escolar e a dificuldade da circunstancia social. Houve a necessidade de replanejar a abordagem dos conteúdos que seriam ministrados, replanejamento frequentemente perante a realidades que aparecem, novas experiencias e invenção do "fazer educação" de forma remota (Oliveira, 2020). Esse processo de fazer educação de forma remota exigiu do professor uma adaptação e superação em diversas situações. É fundamental que no período de pandemia os professores discutam juntos formas de integração das tecnologias digitais de informação e comunicação TDIC ao planejamento e ao currículo escolar, bem como estratégias pedagógicas que promovam a evolução dos alunos de maneira individualizada e coletiva (Ferreira, Magalhães \& Oliveira, 2020).

O Gráfico 8 demostra que, $75 \%$ dos professores da unidade concedente de estágio optaram pelos conteúdos planejados no início do ano letivo.

Gráfico 8 - Conteúdo ministrado pelos professores da unidade concedente de estágio.

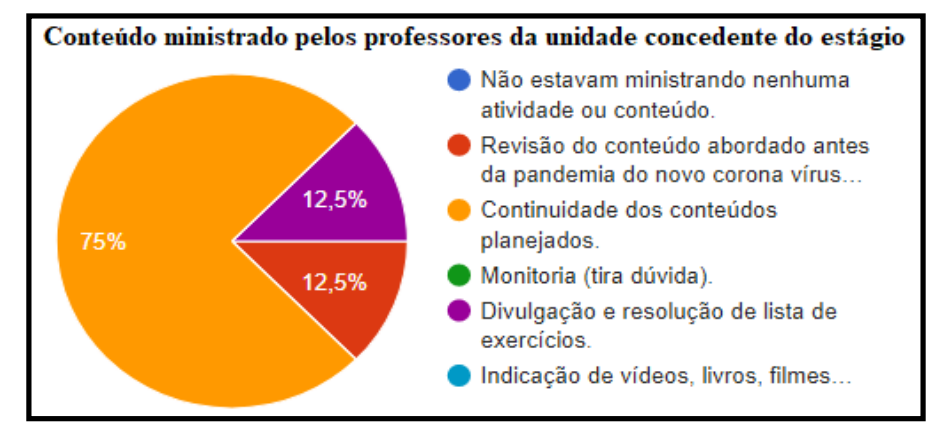

Fonte: Autores (2021).

O Gráfico 8 demostra que os professores da unidade concedente do estágio optaram pela continuidade dos conteúdos planejados no início do ano letivo com adaptações conforme indicado no Gráfico 7. Ainda de acordo com a demonstração do gráfico $8,25 \%$ dos professores da unidade concedente de estagio optaram por revisarem os conteúdos abordado antes da pandemia e ou divulgação e resolução de lista de exercícios sobre os conteúdos ministrados. Os conteúdos planejados na unidade concedente de estágio foram adaptados conforme a organização curricular, de acordo com a concordância e competências essenciais divulgadas na Base Nacional Curricular Comum - BNCC.

Os conteúdos planejados no início do ano letivo foram adaptados para alcançar os melhores resultados na compreensão nas disciplinas lecionadas. Os professores garantiram a continuação dos estudos e avanços na aprendizagem 
tornando os conceitos ensinados em aplicações de situações problemas, oportunizando vivências significativas aos alunos, trazendo uma atuação cada vez maior dos alunos, por meio de investigações, atuações individuais e coletivas e incentivo a participação motivadora.

\subsection{Ministração das aulas da unidade concedente de estágio curricular supervisionado I}

O Gráfico 9, demostram o resultado do questionamento feito aos discentes que concluíram o estágio curricular supervisionado sobre recurso tecnológicos utilizados pelos professores da unidade concedente do estágio para ministrar aulas e se comunicar com os alunos durante o distanciamento social. Segundo o Gráfico 9, é possível observar que 37,5\% dos professores utilizaram vídeo aula como recurso tecnológico para ministrar as aulas.

Gráfico 9 - Recursos tecnológicos utilizado pelos professores da unidade concedente de estagio para ministrar as aulas.

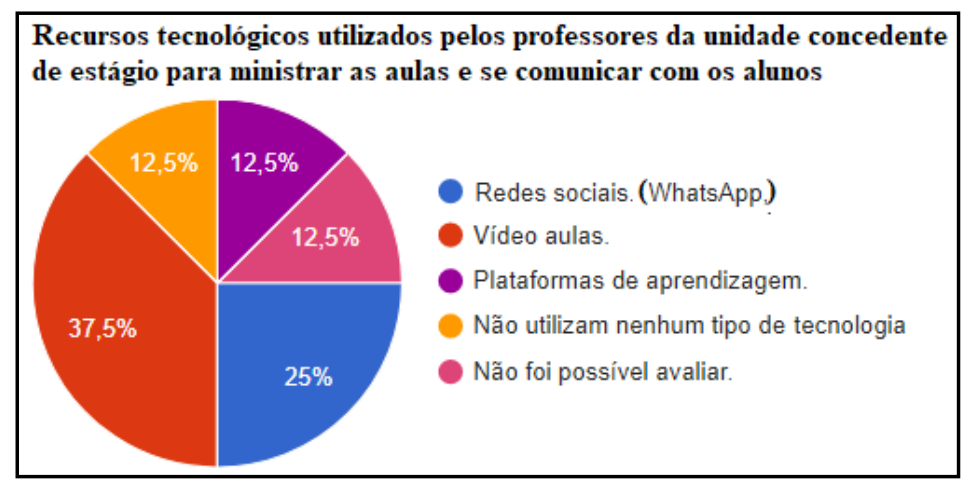

Fonte: Autores (2021).

Ainda segundo o Gráfico 9, é possível ver que 25\% dos professores utilizaram os grupos de WhatsApp para se comunicar com os alunos, passando informações e vídeo aulas dos conteúdos planejados.

A utilização dos meios tecnológicos nas atividades pedagógicas possui um potencial motivador pois um dos fatores que interfere de forma negativa na qualidade da aprendizagem é a falta de motivação dos professores e dos alunos (Caetano, 2015). Sendo assim, o uso das tecnologias colaborar com o aprimoramento e elevação dos níveis de atenção e estimulo dos alunos, ajudando no planejamento, ajudando a dedicação, participação, oportunizando maior interesse pelas aulas desenvolvidas (Branco, Adriano, Zanatta, 2020).

O mundo está cada vez mais digital. É necessário repensar a atuação do docente no sentido de favorecer o letramento digital, capacitando os professores para maior uso e domínio das tecnologias e das várias mídias digitais que fazem parte do novo cenário e desafios contemporâneos da educação (Branco, Adriano, Zanatta, 2020). Bezerra, (2018) define letramento digital como sendo uma ação das utilizações das informações por meio da aplicação das tecnologias digitais de informação e comunicação.

Os recursos tecnológicos lançam vários desafios aos professores, especificamente, quanto busca e nível de informação, na heterogeneidade de recursos e meios, nos modos de aprendizagem, nas formas de comunicação e no novo perfil dos professores. A tecnologia desempenha uma função fundamental e oportuna na aquisição à informação, reduzindo as fronteiras geográficas mundiais possibilitando acesso as informações e consulta de documentos digitais sobre várias temáticas. Para além disso, importa realçar que os processos de aprendizagem foram alvo de profundas alterações nos contextos onde a tecnologia passou a estar presente colocando autonomia no acesso à informação (Caetano, 2015)

Frente a essa situação, fazer-se-á uma reflexão sobre a participação da escola, na solução de problemas de infraestrutura e na oferta de mais recursos tecnológicos para uso pedagógico. Conforme, é necessário melhorias no 
procedimento de formação inicial e continuada dos professores, pretendendo uma melhor preparação para o novo perfil dos professores e do uso das mídias digitais e das TDIC na educação (Branco, Adriano, Zanatta, 2020)

O Gráfico 10, informa sobre o questionamento feito aos discentes sobre os conhecimentos dos professores da unidade concedente do estágio curricular supervisionado I sobre tecnologia digital da informação e comunicação (TDICs). Segundo os discentes estagiários, $62,5 \%$ dos professores da unidade concedente de estágio não tinham formação ou nenhum conhecimento das ferramentas de tecnologia digital da informação e comunicação. O gráfico informa ainda que $25 \%$ dos professores tinham formação ou algum conhecimento sobre as TDICs.

Gráfico 10 - Recursos tecnológicos utilizado pelos professores da unidade concedente de estagio para ministrar as aulas.

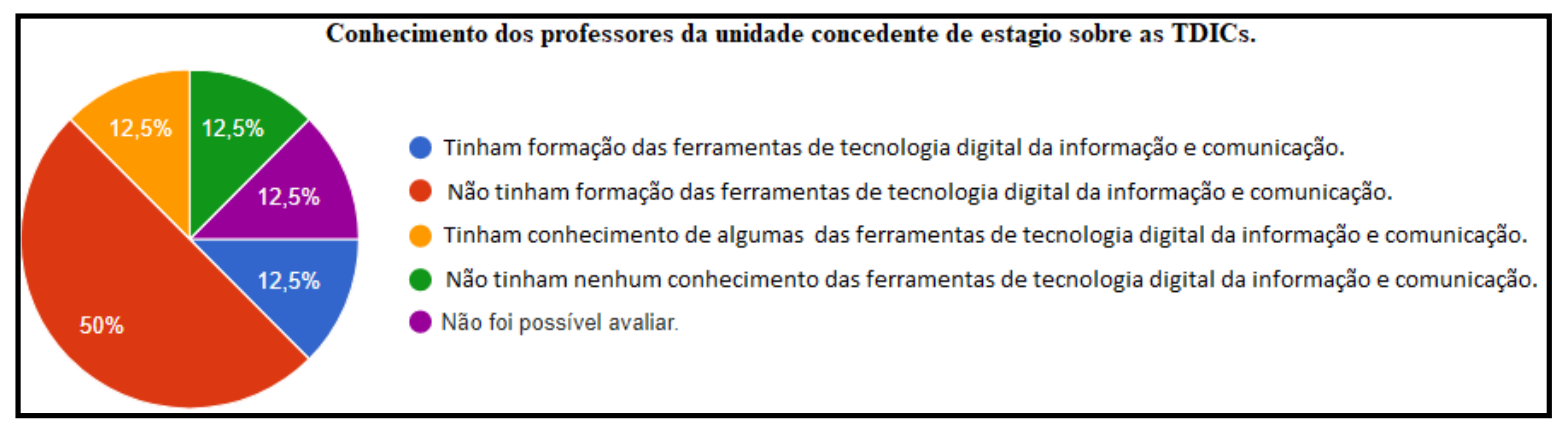

Fonte: Autores (2021).

A globalização interfere na estrutura de educação escolar e desenvolvimento das atividades do professor (Moreira \& Kramer 2007). Esse procedimento está incluído na reforma científico-tecnológica e vinda das TDICs na sala de aula. (Branco, Adriano, Zanatta, 2020). Através de uma formação completa e satisfatória, os professores poderão explorar as ferramentas digitais em sua plenitude e as potencialidades das TDICs (Tarouco, 2019). Deve-se agregar e planejar estratégias para direcionar a formação docente, progressão profissional contínua e contribuição para o aperfeiçoamento do processo de ensino e aprendizagem uma sociedade mais e mais digital.

Segundo Barreto (2004), democratização ao acesso das TDIC promove, direta ou indiretamente, um movimento de recaracterização da prática e da formação do educador.

A presença das TDIC é frequentemente discutida nas atividades pedagógicas, compreendido como o conjunto das práticas de linguagem desenvolvidas no processo de ensino. Nesse horizonte, para que os professores sejam melhor preparados para lidar com tantas mudanças, com os avanços tecnológicos, com as novas mídias e com o perfil dos alunos que vem mudando constantemente é importante repensar e investir mais na formação inicial e na formação continuada (Branco, Adriano, Zanatta, 2020).

Nessa concepção, é imprescindível a reflexão e o debate sobre a formação inicial no curso de licenciatura em Química que possibilite ao futuro professor conhecimento e condições para lecionar utilizando essas tecnologias.

\section{Conclusão}

Diante do exposto, o objetivo deste trabalho é apresentar uma análise das respostas ao questionário aplicado pela Supervisão do Estágio Curricular Supervisionado, do Curso de Licenciatura em Química do IFTO campus Paraíso do Tocantins, aos estudantes matriculados e que concluíram estágio curricular supervisionado I, que devido ao isolamento social ocasionado pela COVID 19, aconteceu de forma remota no $9^{\circ}$ ano do ensino fundamental em uma escola pública estadual.

O Estágio Curricular Supervisionado I é essencial para a formação e qualificação dos futuros professores, estabelecendo se como um período indispensável e impreterível que propõe a evolução do discente estagiário e o 
conhecimento de habilidades na pratica educativa, na qual a teoria integralizada a prática. De fato, o estágio proporciona vivencias e práticas da futura atuação profissional, a introdução no ambiente escolar, a fim de que o discente se relacione com aspectos específicos e técnico, característicos à docência, bem como nas adversidades vivenciadas no contexto escolar.

A análise do questionário aplicados pela supervisão do Curso de Licenciatura em Química aos discentes concluintes do estágio Curricular supervisionado I apontaram que os estudantes optaram por estagiar em escolas públicas, avaliaram respectivamente como ótima e boas as orientações e supervisões recebidas durante o estágio, classificaram como boa as informações fornecidas quanto aos objetivos, procedimentos, relatórios e avaliação do estágio, julgaram como significativos os conhecimentos obtidos nas disciplinas do curso durante e anterior a realização do estágio, que o estágio proporcionou segurança para atuação em sala de aula, a avaliação do ambiente do estágio foi boa, que os professores estavam executando o planejamento anual com adaptações durante o segundo semestre de 2020, ministrando os conteúdos planejados no início do ano letivo e utilizaram vídeo aula como recurso tecnológico para ministrar as aulas e por fim que a maioria dos professores da unidade concedente de estágio não tinham formação ou nenhum conhecimento das ferramentas de tecnologia digital da informação e comunicação.

A importância da realização do Estágio Curricular Supervisionado I para a formação inicial docente, para a supervisão do Curso de Licenciatura em Química bem como sua avaliação não se resume cumprir horas, mas sim oportunizar a vivenciar in loco, despertar a reflexão, criticidade e investigação científica para que o discente inicie sua carreira do magistério com uma formação mais sólida.

Recomenda-se para trabalhos futuros a aplicação de mais questionários com o intuito de obter informações sobre as unidades de ensino concedentes de estágio e o processo formativo, para que o discente inicie sua formação no magistério de forma segura, reflexiva, critica e investigativa.

\section{Agradecimentos}

A Deus, ao Instituto Federal de Educação, Ciência e Tecnologia do Tocantins (IFTO) campus Paraíso do Tocantins pelo apoio dado durante o desenvolvimento das etapas desse trabalho.

\section{Referências}

Almeida F. F. V. de, \& Moreira, E. C. (2020) Planejamento e organização do estágio nos cursos de licenciatura em educação Física de Mato Grosso. Revista Educação, 25(204473), 1-17, http://orcid.org/0000-0003-3831-7700

Almeida, F. F. V., \& Moreira, E. C. (2012). Contribuições da disciplina de estágio supervisionado de um curso de licenciatura em educação física: a percepção discente. Conexões, 10(2), 77-102. https://doi.org/10.20396/conex.v10i2.8637676

Altarugio, M. H., \& Neto, S. de S. (2019). O Papel do Orientador e a Formação do Professor Reflexivo no Estágio Supervisionado da Área de Ciências. Acta Scientiae, 21(4), 174-191. https://doi.org/10.17648/acta.scientiae.v21iss4id4894

Araújo, O. H. A., \& Martins, E. S. (2020). Estágio curricular supervisionado como práxis: algumas perguntas e possíveis de respostas. Revista Reflexão e Ação, 28(1), 191-203. http://dx.doi.org/10.17058/rea.v28i1.120902

Aroeira, K. P., \& Pimenta, S. G. (Orgs.). (2018). Didática e Estágio. Aprris.

Barreto, R. G. (2004). Tecnologia e educação: trabalho e formação docente. Revista Educação \& Sociedade, 25(89), 1181-1201. https://www.scielo.br/j/es/a/6 HmDSHGqC5VC3RSNtYWZmWS/?lang=pt\&format=pdf

Basniak, M. I., \& Paulek, C. M. (2017). O papel do supervisor de estágio na visão dos alunos de um curso de licenciatura em matemática. Anais do XIV Encontro Paranaense de Educação Matemática, Cascavel, Brasil. http://www.sbemparana.com.br/eventos/index.php/EPREM/XIVEP REM/_paper/viewFile/32/65

Bezerra, I. S. (2018). Inclusão digital como forma de cidadania e a lei de acesso à informação. Environmental Smoke, 1(1), 148-161. https://doi.org/10.32435/envsmoke.201811148-161

Berkowitz, R., Moore, H., Astor, R. A., \& Benbenishty, R. (2017) . A Research Synthesis of the Associations Between Socioeconomic Background, Inequality, School Climate, and Academic Achievement. Review of Educational Research, 87(2), 425-469. https://doi.org/10.3102/0034654316669821 
Borssoi, B. L. (2028, 11 a 13 de novembro). O estágio na formação docente: Da teoria a prática, ação-reflexão. Anais $1^{\circ}$ Simpósio Nacional de Educação e XX Semana de Pedagogia, Cascavel, Brasil. https://docplayer.com.br/255975-O-estagio-na-formacao-docente-da-teoria-a-pratica-acao-reflexao.html

Branco, E. Adriano. G., \& Zanatta, S. (2020). Educação e TDIC: Contextos e desafios das aulas remotas durante a pandemia da COVID-19. Revista Debates em Educação, 12(2), 328-350. https://doi.org/10.28998/2175-6600.2020v12nEsp2p328-350.

Brasil, Ministério da Educação, Conselho Nacional de Educação (2015). Resolução CNE/CP 2, de $1^{\circ}$ de julho de 2015. Diretrizes Curriculares Nacionais para a formação inicial em nível superior e continuada. Brasília, DF, 2015. http://portal.mec.gov.br/docman/agosto-2017-pdf/70431-res-cne-cp002-03072015-pdf/file

Cabral, W. A., \& Flôr, C. C. C. (2016). (Re)pensando as práticas de escrita na disciplina de estágio supervisionado em química: Com a palavra, os estagiários. Revista Ensaio, 18(3), 161-174. https://doi.org/10.1590/1983-21172016180308

Carpinteiro, A. C., \& Almeida, J. G. (2008). Módulo 10: Teorias do Espaço Educativo. http://portal.mec.gov.br/seb/arquivos/pdf/profunc/10_espaco.pdf

Caetano, L. M. D., (2015). Tecnologia e Educação: quais os desafios? Educação, 40(2), 295-309. https://www.redalyc.org/articulo.oa?id=117138253003

Costa, P. M. S., Araújo, A. C. L., Moreira, D. N., \& Geglio, P. C. (2019, 5 a 9 de novembro). O estágio curricular na concepção dos estudantes dos cursos de licenciatura em química: uma análise das respostas ao questionário do ENADE. [Apresentação de trabalho]. Anais do $59^{\circ}$ Congresso Brasileiro de Química. João Pessoa. Brasil. http://www.abq.org.br/cbq/2019/trabalhos/6/1942-27643.html

Cruz, D. N. B. da, Silva, E. H. B. da, \& Negreiros, F. (2020) Estágio curricular supervisionado nos anos iniciais: Desafios e perspectivas de estudantes de pedagogia. Revista Educação \& Linguagem, 7(2), 34-46. https://www.fvj.br/revista/wp-content/uploads/2021/02/4_REdLi_2020.2.pdf>

Dourado, L. F. (2016). Formação de profissionais do magistério da educação básica: Novas diretrizes e perspectivas. Comunicação \& Educação, 21(1), 2739. https://doi.org/10.11606/issn.2316-9125.v21i1p27-39

Elali, G. A. (2003). O ambiente da escola-o ambiente na escola: Uma discussão sobre a relação escola-natureza em educação infantil. Revista Estudos de Psicologia, 8(2), 309-319. https://doi.org/10.1590/S1413-294X2003000200013

El Tassa, K. O. M., Boaron, A., Lyczakouvski, T., Pepe, M. A. dos S., Gutervil, J., Ramos, F. L., Falbot, I., Paszko, P. M., \& Machado Neto, J. L. (2015). Estágio supervisionado curricular na formação de professores em educação física: Relato de experiências. Revista Nucleus, 12(2), $281-287$. https://doi.org/10.3738/1982.2278.1434

Ferreira, T. A., Magalhães, M. A., \& Oliveira, C. A. R. de. (2020). Concepções de professores de ensino médio sobre o uso didático-pedagógico de aplicativos educacionais digitais para o processo de ensino e aprendizagem de química e suas limitações. Research, Society and Development,9(12), e23291211156. https://doi.org/10.33448/rsd-v9i12.11156

Fonseca, G. K., Sena, M. C., Mesquita, M. E., \& Paula, J. T. S. dos S. (2019). As Contribuições do estágio supervisionado para a formação do pedagogo. Semioses: Inovação, Desenvolvimento e Sustentabilidade, 13(4), 1-15. https://doi.org/10.15202/1981996x.2019v13n4p82

Freitas, L. de A., \& Monteiro, E. P. (2019). Estágio supervisionado: compartilhando as experiências e os desafios para o ensino de Química no Amazonas. Revista de Educação em Ciências e Matemática, 15(33), 183-200. https://periodicos.ufpa.br/index.php/revistaamazonia/article/view/6049

Instituto Federal de Educação Ciência e Tecnologia do Tocantins (2020). Projeto Pedagógico do Curso de graduação em Licenciatura em Química. Paraíso do Tocantins. http://www.ifto.edu.br/ifto/colegiados/consup/documentos-aprovados/ppc/campus-paraiso-do-tocantins/licenciatura-em-quimica/ppc-licenciatura-em-quimica-campus-pa raiso-do-tocantins.pdf

Imbernón, F. (2017). Formação docente e profissional: formar-se para a mudança e incerteza (9a ed.). Cortez

Iza, D. F. V., \& Souza Neto, S. (2015). The challenges of supervised physical education curricular practicum in the partnership between university and school. Revista Movimento, 21(1), 105-116. http://seer.ufrgs.br/Movimento/article/download/46271/35295

Libâneo, J.C. (2008). Didática. (28 ed.). Cortez.

Marconi, M. A., \& Lakatos, E. M. (2015). Fundamentos de metodologia científica (5a ed.). Atlas

Mauriz, T. R. de M., \& Gomes, G. M., (2019, 24 a 26 de outubro). O estágio supervisionado e o papel do supervisor na avaliação da aprendizagem profissional. [Comunicação Oral] VI Congresso Nacional de Educação, Maceió, Brasil. https://www.editorarealize.com.br/artigo/visualizar/60369

Mól, G. S. (2019). Pesquisa qualitativa em ensino de química. Revista Pesquisa Qualitativa, 5(9), 495-513. https://editora.sepq.org.br/rpq/article/view/140/96

Moreira, A. F. B. \& Kramer, S. (2007). Contemporaneidade, educação e tecnologia. Revista Educação e Sociedade, 28(100), 1037-1057. https://doi.org/10.1590/S010173302007000300019

Nascimento A., M., do \& Anselmo, K., de B. (2012, 20 a 22 de agosto). O estágio curricular obrigatório e o trabalho do professor orientador: Limites e tensões. Anais do VII Seminário Regional de Política e Administração da Educação do Nordeste. Recife. Brasil. https://www.seminariosregionaisanpae.net.br/numero1/1comun icacao/Eixo0437/Ana\%20Maria\%20do\%20Nascimento_res_GT4.pdf

Oliveira, M. Q. de. (2020). Docência na Educação Básica em tempos de pandemia: Ações, estratégias pedagógicas e desafios enfrentados no ano letivo de 2020 da Escola Integral Professora Ana Cristina Rolim Machado. Research, Society and Development, 9(12), e47391211466. https://doi.org/10.33448/rsdv9i12.11466

Oliveira, R. M. de. (2019). Estágio supervisionado ensino médio: planejamento e docência. Revista Científica Multidisciplinar Núcleo do Conhecimento, 4(6), 243-272. https://www.nucleodoconhecimento.com.br/pedagogia/planejamento-e-docencia 
Research, Society and Development, v. 10, n. 10, e168101018695, 2021

(CC BY 4.0) | ISSN 2525-3409 | DOI: http://dx.doi.org/10.33448/rsd-v10i10.18695

Pimenta, S. G, \& Lima, M. S. L. (2012). Estágio e docência (7a ed.). Cortez

Rocha, L. dos S. (2018). Estágio de regência no ensino médio com turmas da EJA: reflexões da prática docente e uso do lúdico nas aulas de biologia. Revista Científica Multidisciplinar Núcleo do Conhecimento, 8(3), 116-123. https://www.nucleodoconhecimento.com.br/pedagogia/estagio-de-regencia

Rocha, E. do A., \& Silva, A. J. N. da. (2020). O estágio curricular supervisionado de observação: Tecendo reflexões e refletindo sobre esse espaço de formação. Revista Científica Multidisciplinar Núcleo do Conhecimento, 5(7), 61-71. https://doi.org/10.32749/nucleodoconhecimento.com.br/educacao/estagiocurricular

Saviani D. (2013). História das ideias pedagógicas no Brasil (4a ed.). Autores Associados

Silva, I. C. T. da, Siqueira, V. F., \& Goi, M. E. J. (2019). Relatos de Estágio Supervisionado no Ensino de Química. Revista Debates Em Ensino De Química, 5(2), 39-54. http://www.journals.ufrpe.br/index.php/REDEQUIM/article/view/2417

Souza, E. M. de F., \& Ferreira, L. G. (2019). A prática como componente curricular: (Re)indagações para a formação docente. Revista Práxis Educacional, 15(34), 195-210. https://doi.org/10.22481/praxisedu.v15i34.5505A.

Tarouco, L. M. R. (2019). Competências digitais dos professores. In: A. F. Barbosa. (Org.). Pesquisa sobre o uso das tecnologias de informação e comunicação nas escolas brasileiras: TIC educação 2019 (pp. 33-44). Comitê Gestor da Internet no Brasil.

Tessaro, P. S., \& Maceno, N. G. (2017). Estágio Supervisionado em Ensino de Química. Revista Debates Em Ensino De Química, 2(2), 32-44. http://www.journals.ufrpe.br/index.php/REDEQUIM/article/view/1313

Veiga, I. P. da. (1998). Projeto político-pedagógico da escola: uma construção coletiva. In: I. P. da Veiga (org.). Projeto político-pedagógico da escola: uma construção possível (pp. 11-35). Papirus 